\title{
Heat transfer enhancement in a fin and tube heat exchanger with isosceles vortex generators
}

\author{
D. Sahel*, R. Benzeguir**, T. Baki*** \\ *Gas Fuels and Environment Laboratory, Mechanical Engineering Faculty, University of Sciences and the \\ Technology-Oran, USTO-MB, BP 1505, El-M’Naouer, Oran 31000, Algeria, E-mail: djamel_sahel@ymail.com \\ **Gas Fuels and Environment Laboratory, Mechanical Engineering Faculty, University of Sciences and the \\ Technology-Oran, USTO-MB, BP 1505, El-M'Naouer, Oran 31000, Algeria, E-mail: benzeguir_redouane@yahoo.fr \\ ***Gas Fuels and Environment Laboratory, Mechanical Engineering Faculty, University of Sciences and the \\ Technology-Oran, USTO-MB, BP 1505, El-M'Naouer, Oran 31000, Algeria, E-mail: tou_baki@hotmail.com
}

cross $^{\text {ref }}$ http://dx.doi.org/10.5755/j01.mech.21.6.12240

\section{Nomenclature}

$A$ - total heat transfer surface area, $\mathrm{m}^{2} ; C_{p}$ - specific heat, $\mathrm{J} /(\mathrm{kg} \mathrm{K}) ; D_{c}$ - tube outside diameter, $\mathrm{m} ; D_{h}$-hydraulic diameter, $\mathrm{m} ; f$ - friction factor; $h$ - heat transfer coefficient, $\mathrm{W} /\left(\mathrm{m}^{2} \mathrm{~K}\right) ; k$ - thermal conductivity, $\mathrm{W} /\left(\mathrm{m}^{2} \mathrm{~K}\right) ; N$ - number of tube row; $\mathrm{Nu}$-Nusselt number; $m_{f}$-mass flow rate, $\mathrm{kg} / \mathrm{s} ; \Delta P$ - pressure drop, $\mathrm{Pa} ; P_{l}$ - longitudinal pitch, $\mathrm{m}$; $P r$ - Prandtl number; $P_{t}$ - transverse pitch, m; $Q$ - heat transfer rate, $\mathrm{W} ; U_{m}$ - mean velocity at the minimum flow cross-sectional, $\mathrm{m} / \mathrm{s} ; R e$ - Reynolds number; $T$-temperature, $\mathrm{K}$; greek letters -

$\delta$ - VGs thickness, m; $\alpha$ - attack angle of VGs, deg; $\mu$ - dynamic viscosity, $\mathrm{kg} /(\mathrm{ms}) ; \rho$ - density, $\mathrm{kg} / \mathrm{m}^{3}$;

subscript -

in - inlet; $m$ - mean; out - outlet; $w$ - wall;

abbreviations -

IVGs - Isosceles Vortex Generators; LVGs - longitudinal vortex generators; RVGs - rectangular vortex generators; $T P F$ - Thermal Performance Factor; VGs - vortex generators.

\section{Introduction}

The fin-and-tube heat exchangers are equipment largely used in the different industrial processes such as automobile radiators, air conditioning systems, refrigeration, petrochemical and other technology fields. Heat exchanger performance is limited by the gas side. For liquid fluid flow to air flow and phase change heat exchangers, the air side convection resistance is habitually dominant due to the air thermo-physical properties because heat transfer rates are fundamentally inferior for the gas side than for liquid. Thus, for enhance the thermal performances, it is necessary to put in consideration the impact of the thermo-physical properties of fluid, also the geometrical configuration of the fin-and-tube heat exchangers. For decades, a very successful technique of enhancing the heat transfer performance of air-side is using vortex generators (VGs). The VGs are designed to cause the turbulence intensification, and boundary-layer destruction; heat transfer is enhanced due to these effects.

A several experimental and numerical works effected to improve the heat transfer performance of the finand-tube heat exchangers. Zhou and Ye [1] proposed a curved trapezoidal design as new winglets vortex genera- tors. The experimental results show that the using of the winglets curved trapezoidal enhances the heat transfer coefficient compared with the rectangular winglet. Wang et al $[2,3]$ conducted a series of experiments to study the effect of vortex generators on the flow structure in a fin and tube heat exchangers. They found that the configuration analyzed created a penalty of pressure drop tend to $25-55 \%$ compared with the flat fin geometry. In addition, there are an available works in literature witch improved the heat transfer phenomenon in the fin-and-tube heat exchangers using the vortex generators (see, [4-15]). For example, Fiebig et al [8] tested the effect of delta winglets VGs on heat transfer and pressure drop in a fin and tube heat exchanger. Four configurations were investigated, an inline and a staggered arrangement, each with plain fins and with fins with a pair of vortex generators behind each tube. They reported that the inline tube arrangement the VGs increase the heat transfer by $55-65 \%$ with a corresponding increase of $20-45 \%$ in the friction factor.

He et al [16] numerically examine the effect of a pair of winglets vortex generators for different angles of attack $\left(\beta=10^{\circ}, \beta=20^{\circ}, \beta=30^{\circ}\right)$. They concluded that the rows of discontinuous winglets show a significant increase of heat transfer coefficient tend to $33.8-70.6 \%$, also generated a pressure drop penalty of $43.4-97.2 \%$ for the $30^{\circ}$ attack angle compared with the flat fin. In other hand, the continuous winglets rows provided an adequate heat transfer enhancement of $36.7-81.2 \%$ and associated 60.7$135.6 \%$ of pressure drop. In the same context, Li et al [17] concluded that the arranged LVGs positioned radiantly on the fin surface can guide the main fluid flow to the tube wall and enhance air side heat transfer in the fin and tube heat exchanger. Gholami et al [18] proposed three shapes of vortex generators: rectangular, wavy winglets, a conventional rectangular winglet and tube without winglets for validated and compared the results. The calculations of air flow side presented for Reynolds numbers ranging from 400 to 800 . They concluded that the wavy rectangular winglet can significantly enhance the heat transfer in the fin-and-tube heat exchanger with moderate pressure loss penalty.

In order to understand the fundamental relationship between the increases of local heat transfer and the flow structure in a fin-and-tube compact heat exchangers (LVGs), Chu et al [19] proposed three geometric parameters of longitudinal vortex generators (ascending and descending) wherein the attack angle $(\alpha)$ equal to $15^{\circ}, 30^{\circ}$, 
$45^{\circ}$ and $60^{\circ}$ as the number of tube row (2, 3, 4 and 5). They reported that the attack angle is a critical factor influencing on the velocity and temperature fields. Li et al [20] offered several geometric configurations of longitudinal vortex generators (LVGs). They concluded that the LVGs on plain fins increases the Unset number by $20 \%$ compared with plain fins tube without LVGs. However, the pressure losses penalty due to the using of the VGs in the fin-andtube heat exchangers need to search other configurations to ensure a better heat transfer performance at lowest energy cost. Most of the works existing in literature using the winglets which will guide the flow towards the tube walls leading to the increase in the coefficients of heat transfer. However, the major problems of the exploitation of the winglets in the heat exchangers is the pressure losses due to the bulk flow mixing, change of the flow direction, and formation of the zones of the flow recirculation behind the tubes and the winglets. The principal objective of this article is to find a configuration more efficient to ensure a better coefficient of heat transfer, also to reduce the pressure drop of air side flow in the fin-and-tube heat exchanger. The configurations proposed are a vortex generators of isosceles shape of attack angles $\alpha=5^{\circ}, 10^{\circ}, 15^{\circ}, 25^{\circ}, 35^{\circ}$ and $45^{\circ}$. Two other cases of VGs available in the literature (tube without VGs or Baseline, and of Flat RVG cases [18]) presented in this study to validate and compare the results. The numerical investigations based on the ANSYS FLUENT software. The air is the fluid using to test the effect of the isosceles vortex generators (IVGs) on the performances of the fin-and-tube heat exchangers

\section{Model descriptions}

2.1. Tubes and vortex generators configurations
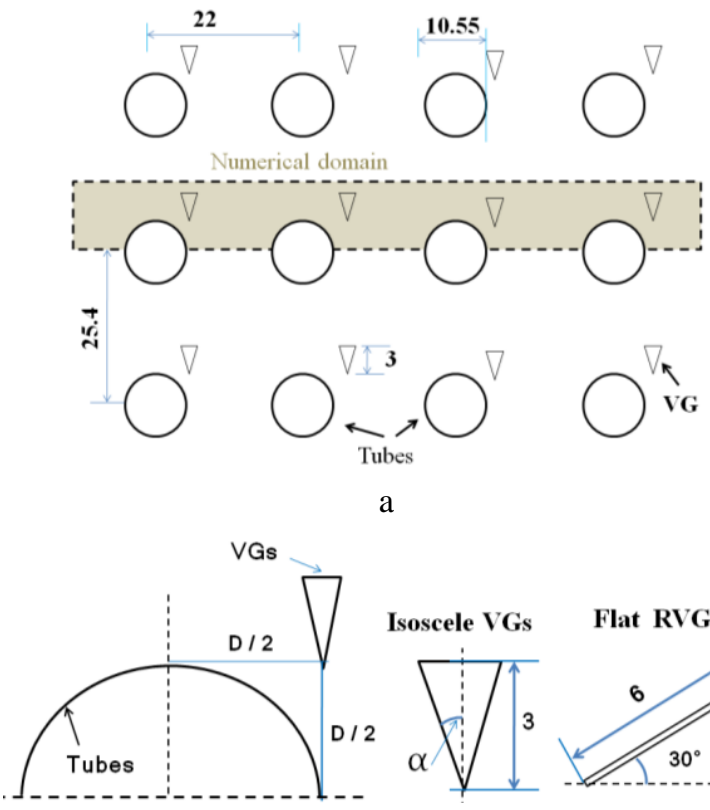

Isoscele VGs Flat RVGs

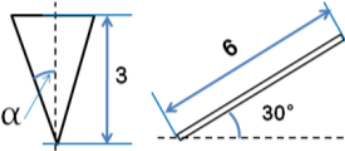

$\mathrm{b}$

Fig. 1 Fin-and-tube heat exchanger computational domain with different forms of winglet vortex generators. All dimensions are in $\mathrm{mm}$, a - configuration of heat exchanger with isosceles vortex generators; $b$ - position of vortex generators

The numerical model adapted for fin-and-tube heat exchangers provided with isosceles vortex generators is illustrated in Fig. 1. The configuration of the geometry allows us used the option of symmetry to reduce the computation time.

The position of the isosceles vortex generator base is given by $D_{X}=D / 2$ and $D_{Y}=D / 2$ as shown in Fig. 1, b. The tube outer diameter $\left(D_{c}\right)$ is $10.55 \mathrm{~mm}$, the transverse tube pitch $\left(P_{t}\right)$ is $25.4 \mathrm{~mm}$, and the longitudinal tube pitch $\left(P_{t}\right)$ is $22 \mathrm{~mm}$. The Flat RVG case is presented by the same dimensions offered by Gholami et al [24] wherein the length $(L)$, the thickness $(\delta)$ and angle of attack $(\beta)$ are $6.0 \mathrm{~mm}, 0.2 \mathrm{~mm}$ and $30^{\circ}$, respectively. In the present study, the vortex generator length is $3 \mathrm{~mm}$, the attack angles of isosceles vortex generator $\alpha$ equal to $0^{\circ}$ (simple VG), $5^{\circ}, 10^{\circ}, 15^{\circ}, 25^{\circ}, 35^{\circ}$ and $45^{\circ}$. For more information, Wahid et al [21] presented in detail the geometry of the tubes.

The numerical model for fluid flow and heat transfer the fin tube of compact heat exchanger was developed under the following assumptions:

- steady two-dimensional fluid flow and heat transfer;

- the flow is laminar and incompressible;

- constant thermo- physical properties fluid properties;

- negligible radiation heat transfer;

- constant temperature of tube surface.

Based on the above assumptions, the tube flow is governed by the continuity, the Navier-Stokes equations and the energy equation. For numerical analysis in this article can be written as [23, 24]:

- Continuity equation:

$$
\frac{\partial}{\partial x_{i}}\left(\rho u_{i}\right)=0 \text {; }
$$

- Momentum equation

$$
\frac{\partial}{\partial x_{i}}\left(\rho u_{i} u_{j}\right)=\frac{\partial}{\partial x_{i}}\left[\mu\left(\frac{\partial u_{j}}{\partial x_{i}}\right)\right]-\frac{\partial p}{\partial x_{j}} ;
$$

- Energy equation:

$$
\frac{\partial}{\partial x_{i}}\left(\rho u_{i} T\right)=\frac{\partial}{\partial x_{i}}\left(\frac{k}{C_{p}} \frac{\partial u_{j}}{\partial x_{i}}\right) \text {. }
$$

In order to validate the dependability of the present numerical method, the numerical investigation is conducted for a fin and tube heat exchanger with the convective heat transfer coefficient of laminar air flow at uniform surface temperature of tubes, experimental data approved by Zukauskas [22] recommended the following correlation:

$$
N u_{D}=0.9\left[0.52 \operatorname{Re}_{D}^{0.5} \operatorname{Pr}^{0.36}\left(\operatorname{Pr} \operatorname{Pr}_{w}\right)^{0.25}\right] .
$$

\subsection{Governing parameters}

A number of parameters are defined as follows $[18,25]$ :

$$
\begin{aligned}
& R e=\rho U_{m} D_{h} / \mu, \\
& Q=m_{f} C_{p}\left(T_{\text {out }}-T_{\text {in }}\right),
\end{aligned}
$$




$$
\begin{aligned}
& \Delta T_{l m}=\frac{\left(\left(T_{\text {wall }}-T_{\text {in }}\right)-\left(T_{\text {wall }}-T_{\text {out }}\right)\right)}{\ln \left(\left(T_{\text {wall }}-T_{\text {in }}\right)-\left(T_{\text {wall }}-T_{\text {out }}\right)\right)}, \\
& Q=\dot{m}_{f} C_{p}\left(T_{\text {wall }}-T_{\text {in }}\right) /\left(A \Delta T_{\text {lm }}\right), \\
& u=h D_{h} / k, \\
& \Delta P=P_{\text {in }}-P_{\text {out }}, \\
& f=\Delta P /\left(0.5 \rho U_{m}{ }^{2}\right) .
\end{aligned}
$$

The thermal performances factor is given by:

$$
T P F=\left(N u / N u_{0}\right) /\left(f / f_{0}\right)^{1 / 3} .
$$

\subsection{Boundary conditions}

The velocity and temperature Profiles are identified at the inlet section. At the inlet a uniform velocity $U=U_{\text {in }}$ and constant temperature $T_{\text {in }}=300 \mathrm{~K}$ are utilized. At the outlet, the Neumann boundary conditions used for all variables, so the streamwise variable gradients are set to be zero. At the sides, symmetry boundary conditions are used by boundary fitted conditions. Impermeable boundary and no-slip wall conditions have been implemented over the tube wall as well as the vortex generators. The constant temperature wall tubes $\left(T_{W}\right)$ is maintained at $350 \mathrm{~K}$ while the VGs are assumed at adiabatic wall conditions.

\subsection{Numerical methods and grid independence validation}

A series of grid tests effected on the all numerical domain are presented in this work. Fig. 2 illustrates a triangular grids type, no uniform, refined near of the tubes walls and the vortex generators to detect the gradients of temperature and velocity. The series of grid chosen in the case of tubes without VGs (Baseline) with $R e=500$ is 64253, 91891, 111980, 145896 and 181442.

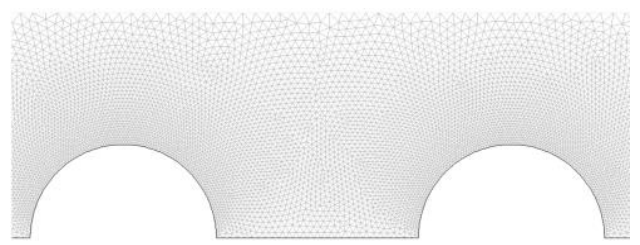

a

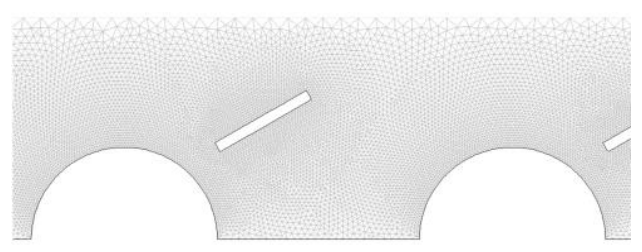

b

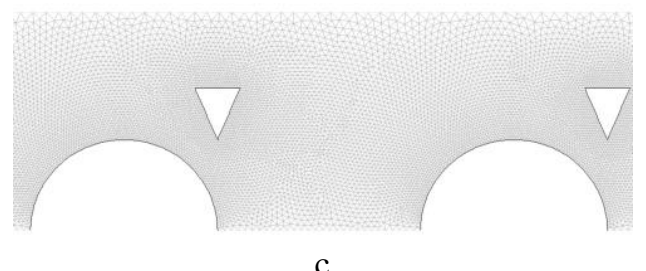

Fig. 2 Grid generation around compact heat exchangers and tubes for different vortex generators: a - base line case; b - Flat RVG case; - isosceles VG with $25^{\circ}$
From 111980 nodes, the variation of the Nusselt number is not significant (do not exceed 2\%) in the increases of the grid density. Therefore, for following calculations, the final accepted grid number is 111980 nodes. In the same way, the same approach performed on the other configurations.

ANSYS FLUENT is the computational fluid code used to calculate the fluid flow and heat transfer in the computational domain. The finite volume method employed on the computational domains to solve the NavierStokes and energy equations using the SIMPLE algorithm. For the solution algorithm, the second order scheme is selected to discretize the convective terms in governing equations. Default under-relaxation factors of the solver are employed. The criterion of convergence is that the normalized residuals are fixed at $10^{-5}$ for the flow equations and $10^{-9}$ for the energy equation.
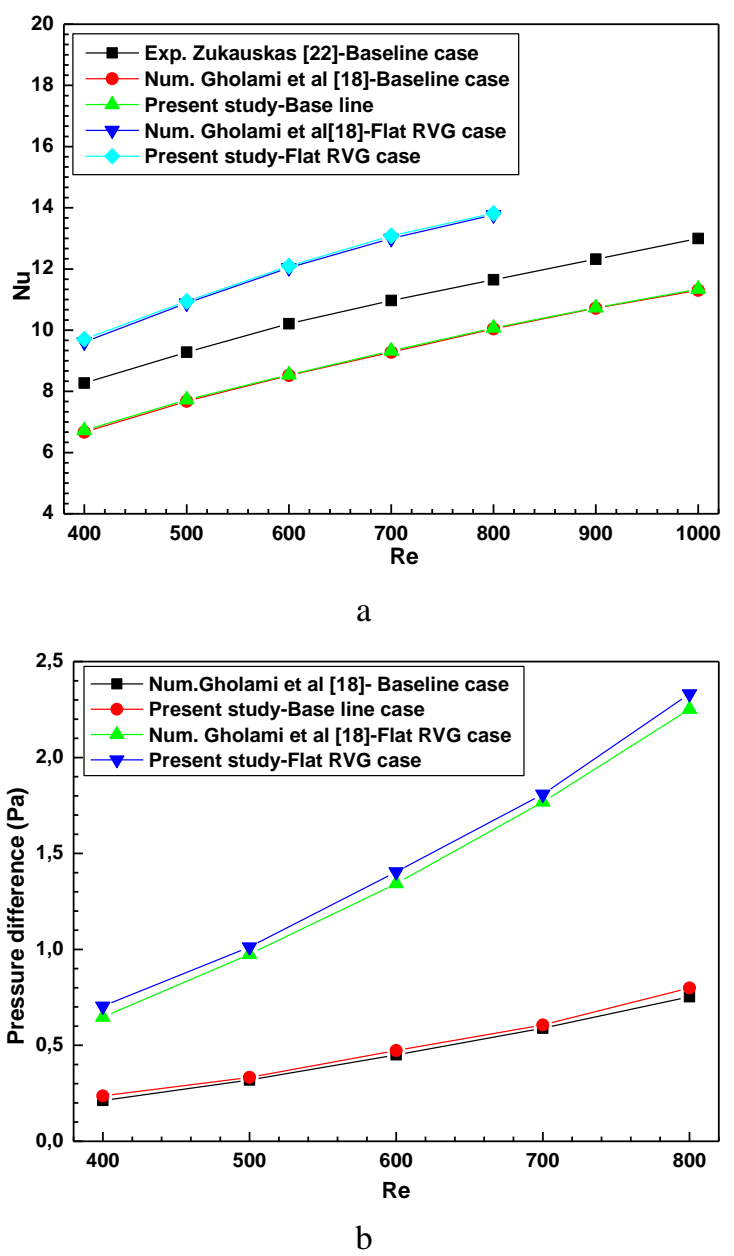

Fig. 3 Verification of: a - Nusselt number; b-pressure drop

\section{Results and discussion}

\subsection{Validation of model and numerical method}

After the grid tests of various numerical domains, the flow and heat transfer characteristics are compared with available results. The present simulation is effected for fin-and-tube heat exchangers with the same geometric dimensions also the thermo-physical properties of fluid as that presented numerically by Gholami et al. [18], and experimentally by Zukauskas [22]. Fig. 3, a and b shows 
comparison between the present numerical work and the past data from previous works available for steady state flow conditions in the literature for Baseline and Flat RVG cases. The comparison of results based on the Nusselt number $(N u)$ and the pressure difference $(\Delta P)$. The figure shows a good conformity between the present results and that reported numerically by Gholami et al [18]. As it can be shown in Fig. 3, a, the Nusselt number agrees well with the available correlations of $\pm 13 \%$ in comparison with Zukauskas data [22].

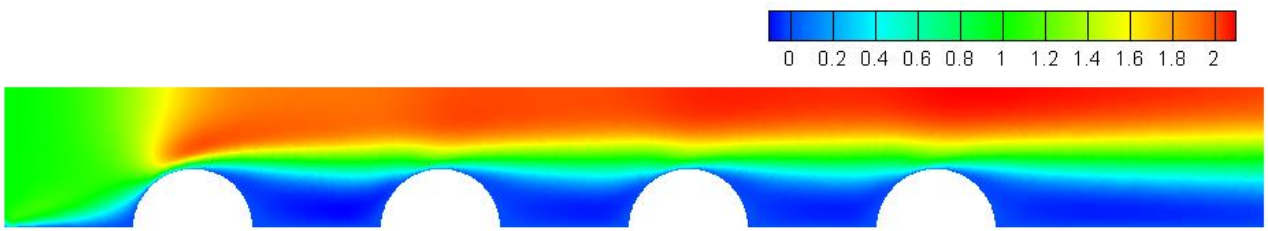

a
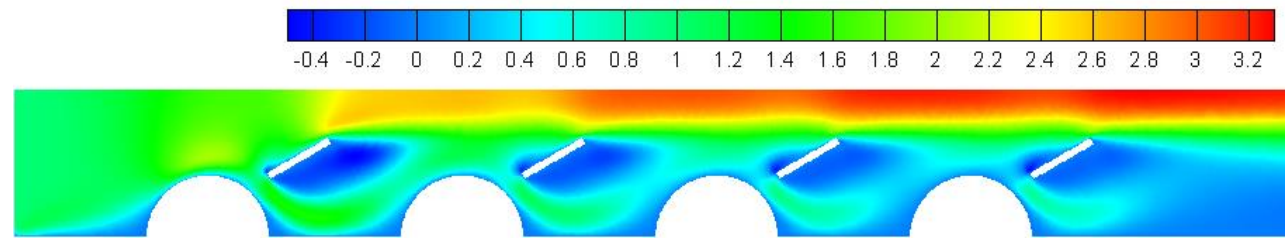

b

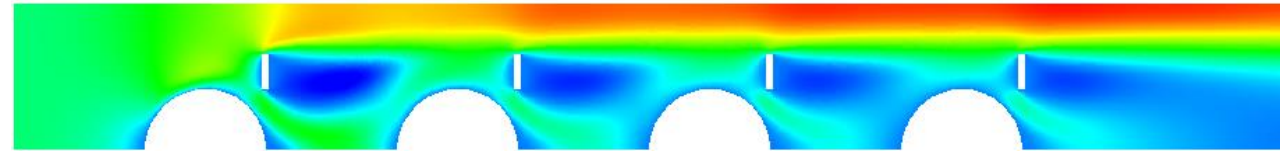

c

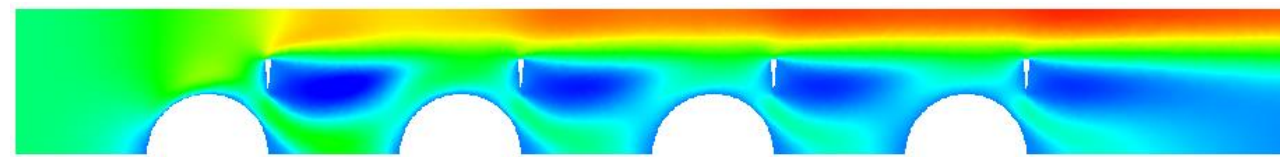

d

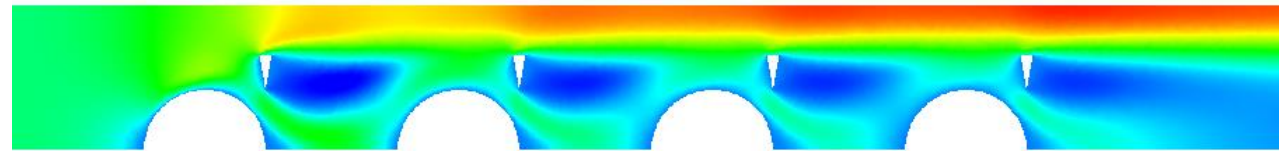

e
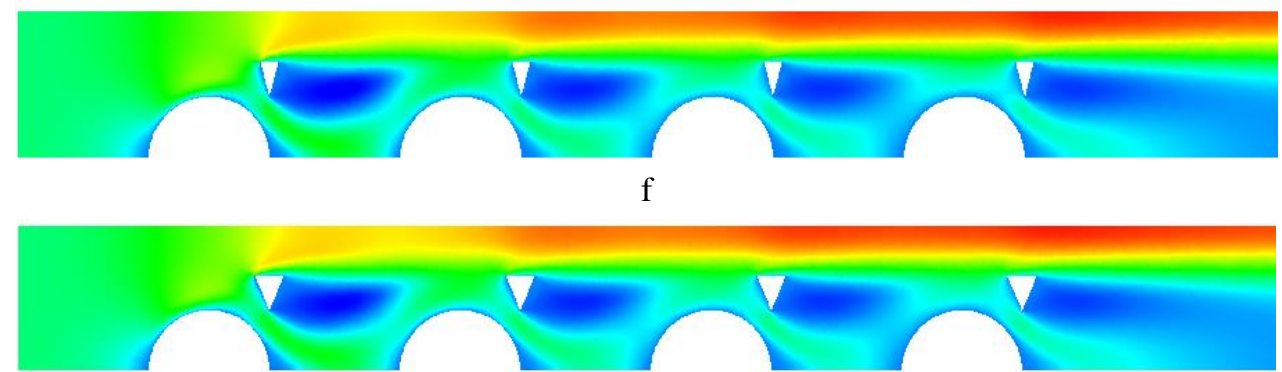

g

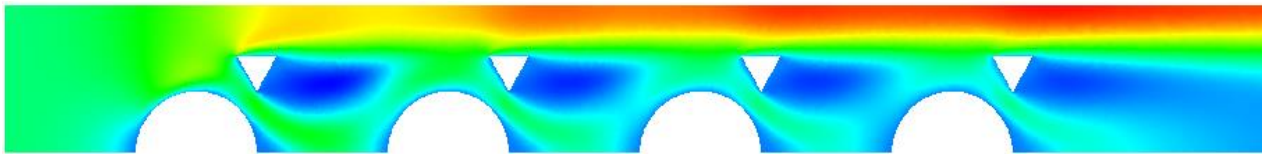

$\mathrm{h}$

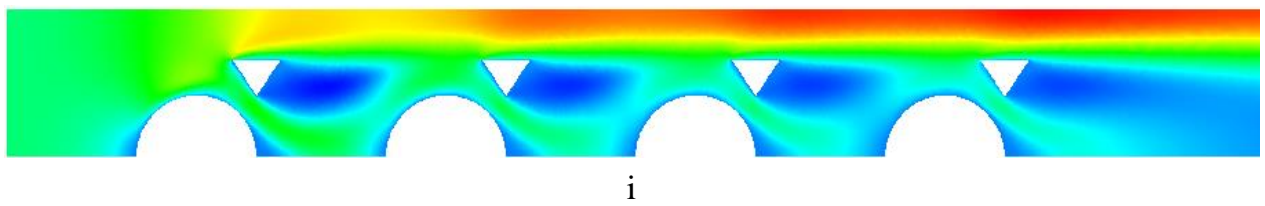

Fig. 4 Axial velocity distributions $u_{x} / u_{\text {in }}$ for different VGs at $R e=500$

\subsection{Flow field}

The flow field around the tubes and vortex generators is illustrated in Fig. 4. This figure shows the axial velocity contours at $R e=500$ for all configurations (Baseline, Flat RVG, isosceles VGs with attack angles $\alpha=5^{\circ}$, $10^{\circ}, 15^{\circ}, 25^{\circ} 35^{\circ}$ and $45^{\circ}$ ) tested in this work. The stagnation of the flow behind the tubes is clearly appearing in the 
case of tubes without vortex generators (Baseline). This case illustrates the problem of low-velocity of the fluid back the tubes that reduce the thermal performances of heat exchanger. Correcting this problem is presented in other configurations where the insertion of the isosceles vortex generators eliminates the zones of low-velocity behind the tubes. During the passing of the flow through the tube walls and vortex generators, the fluid flow separates into three primary zones: a very large zone located between VGs and the tube walls, where the flow is accelerated and swirl the stagnated fluid behind the tubes. The second zone located over VGs that presents the majority of the flow fields. The third region behind the VGs shows a zone of secondary recirculation of the flow.

\subsection{Heat transfer}

Fig. 5 shows the distribution of the temperature field for all geometries at $R e=500$. In the case of tube without vortex generator (Fig. 5, a), the formation of hot points appears clearly behind the tubes, since the fluid stagnant in these regions. In other hand, if we add the VGs near the surface of tubes (Fig. 5, b-i), the fluid flows behind the tubes and significantly eliminates the hot points, which enhance the thermal performances of the fin and tubes heat exchangers.

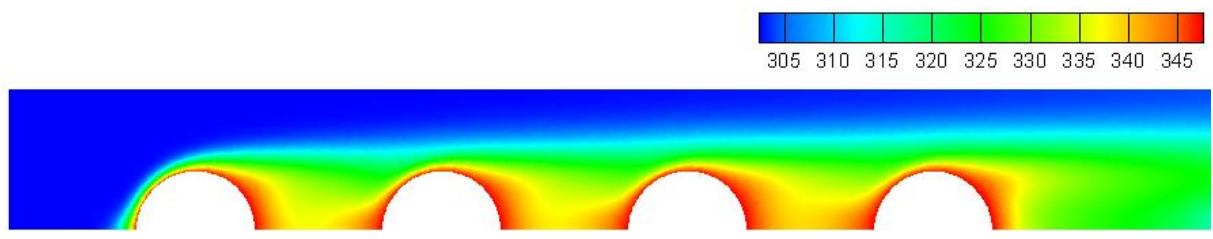

a

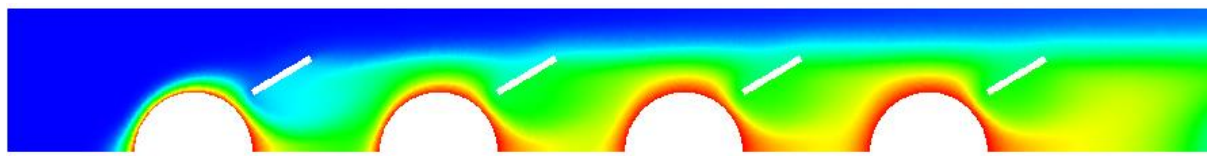

b
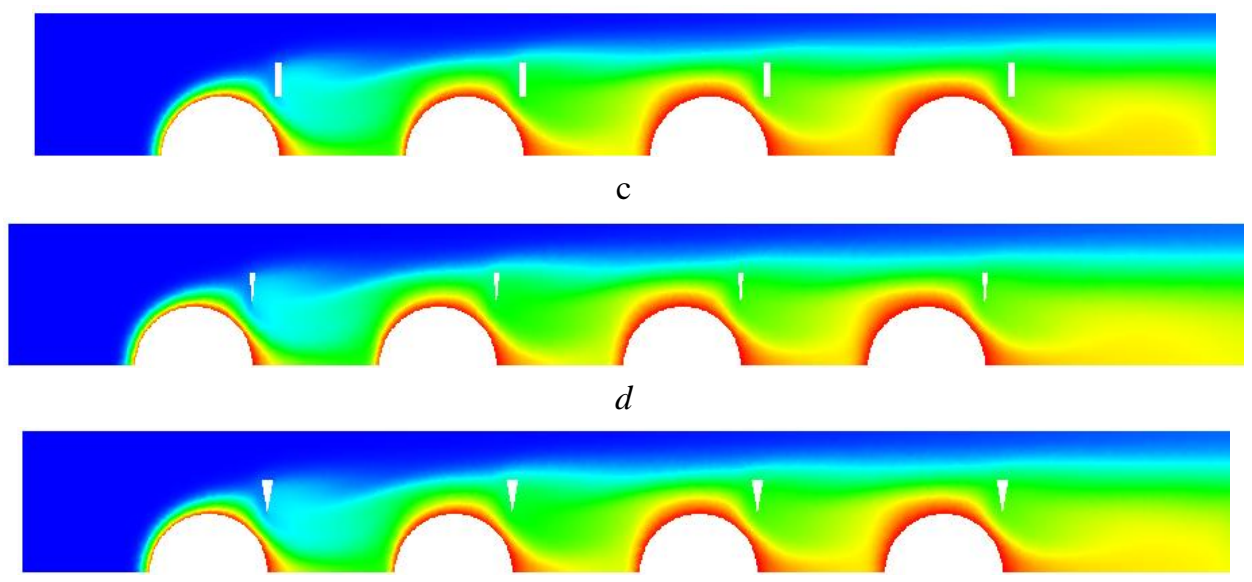

$e$
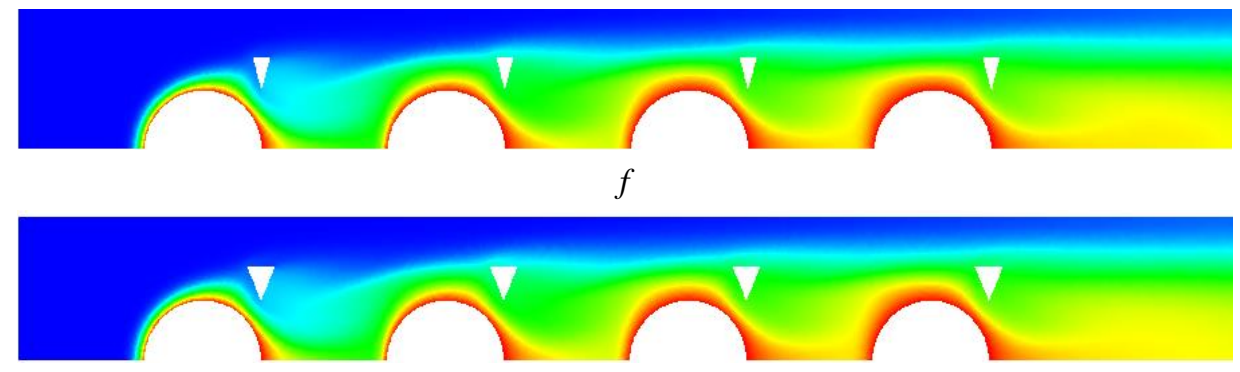

$g$
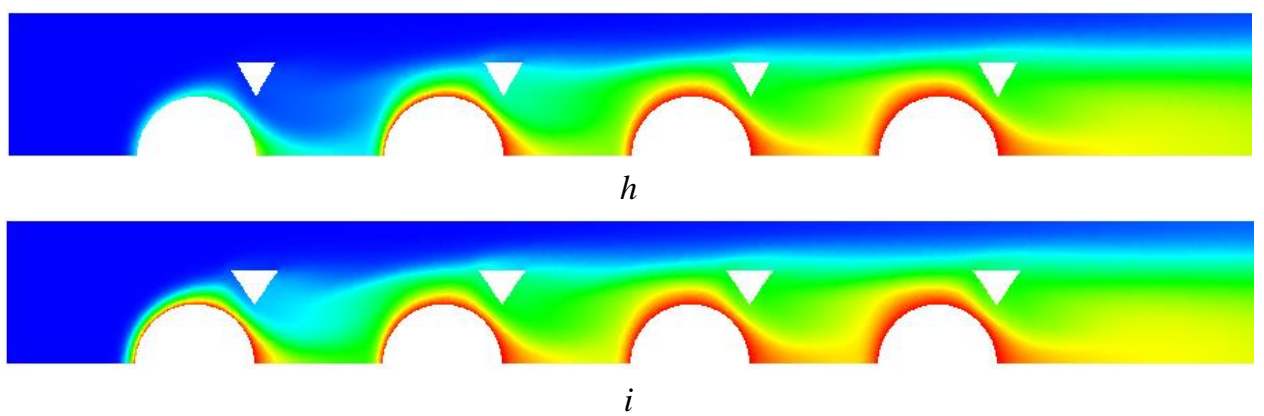

Fig. 5 Temperature distributions for different VGs at $R e=500$ 
The variation of the Nusselt number $(\mathrm{Nu})$ for various Reynolds numbers ranged from 400 to 800 for all configurations is shown in Fig. 6. It is clear that the values for the Nusselt tend to increase with increasing of Reynolds numbers, which induces an improvement in the heat transfer coefficients in the heat exchangers. In the cases of the angle of attack $\alpha=5^{\circ}, 10^{\circ}, 15^{\circ}, 25^{\circ}$ and $45^{\circ}$, the values of the Nusselt Number are almost identical, varying from 9.5 to 14.5 for the Reynolds number ranging from 400 to 800. The Unset number reaching a peak of $9 \%$ and $50 \%$ compared with Flat RVG and Baseline cases, respectively, for $R e=800$. A significant enhancement in heat transfer coefficient is observed for $\alpha=0^{\circ}$ (simple VG), reaching a percentage of $69 \%$ and $95 \%$ compared with Flat RVG and Baseline (tube without VGs) cases, respectively; where $\alpha=35^{\circ}$ takes a percentage of $19 \%$ and $31 \%$ compared with the configurations studied. From the results in Fig. 6, a modified correlation (Eq. 13) is proposed to predict the average Nusselt numbers in the Baseline case (tubes without generator vortex):

$$
\left.\begin{array}{l}
N u=0.461 \operatorname{Re}_{D}^{0.587} \operatorname{Pr}^{2.453}\left(P r / P r_{w}\right)^{0.250}, \\
\text { for } 400 \leq R e \leq 800 .
\end{array}\right\}
$$

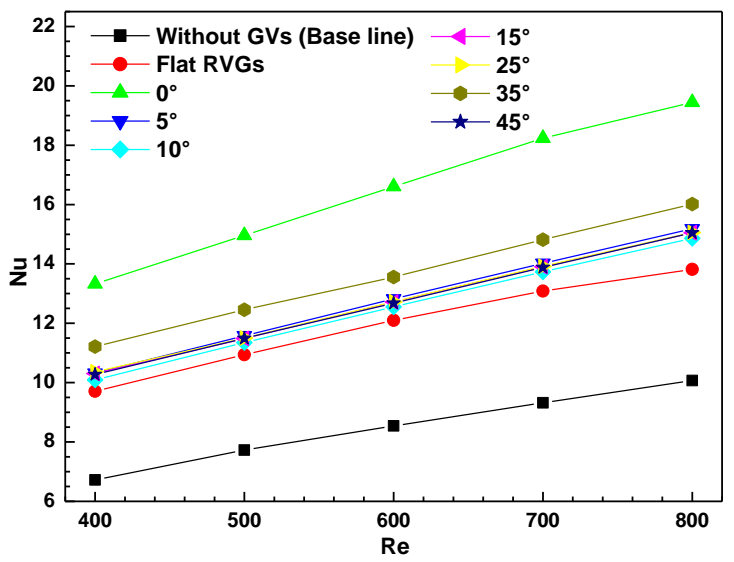

Fig. 6 Variation of $\mathrm{Nu}$ with Reynolds number for various VGs

\subsection{Pressure drop}

Usually, the increases in heat transfer create a pressure drop. However, in this study, we were able to minimize the pressure drop and keeping the thermal performance to high levels. Fig. 7, a and b shows the variation of pressure difference that tends to augment with the rise of the Reynolds number values.

Using Flat RVG leads to extreme increase of the friction factor of about 3 times higher than that the tube without vortex generators (Baseline case), at $R e=700$. Comparing with the Baseline case, the cases of attack angles $\alpha=0^{\circ}, 5^{\circ}, 10^{\circ}, 15^{\circ}, 25^{\circ}, 35^{\circ}$ and $45^{\circ}$ give an interval of friction factor values vary from 2.4 to 2.8 for $R e=700$, where the weak value observed in the case of $\alpha=0^{\circ}$, when the cases of $\alpha=15^{\circ}$ and $45^{\circ}$ assured the highest value.

\subsection{Performance evaluation}

In the same conditions, the Nusselt number achieve a values tend to 19.5 and 14 for $\alpha=0^{\circ}$ and Flat RVG cases, where the VG size equal to $3 \mathrm{~mm}$ and $6 \mathrm{~mm}$, respectively. However, the use of the Flat RVG case provide an extreme increase of the friction factor attain to 3 times, while this values arrive to 2.8 times for the $\alpha=0^{\circ}$ case compared with the tube without vortex generators, at $R e=800$.
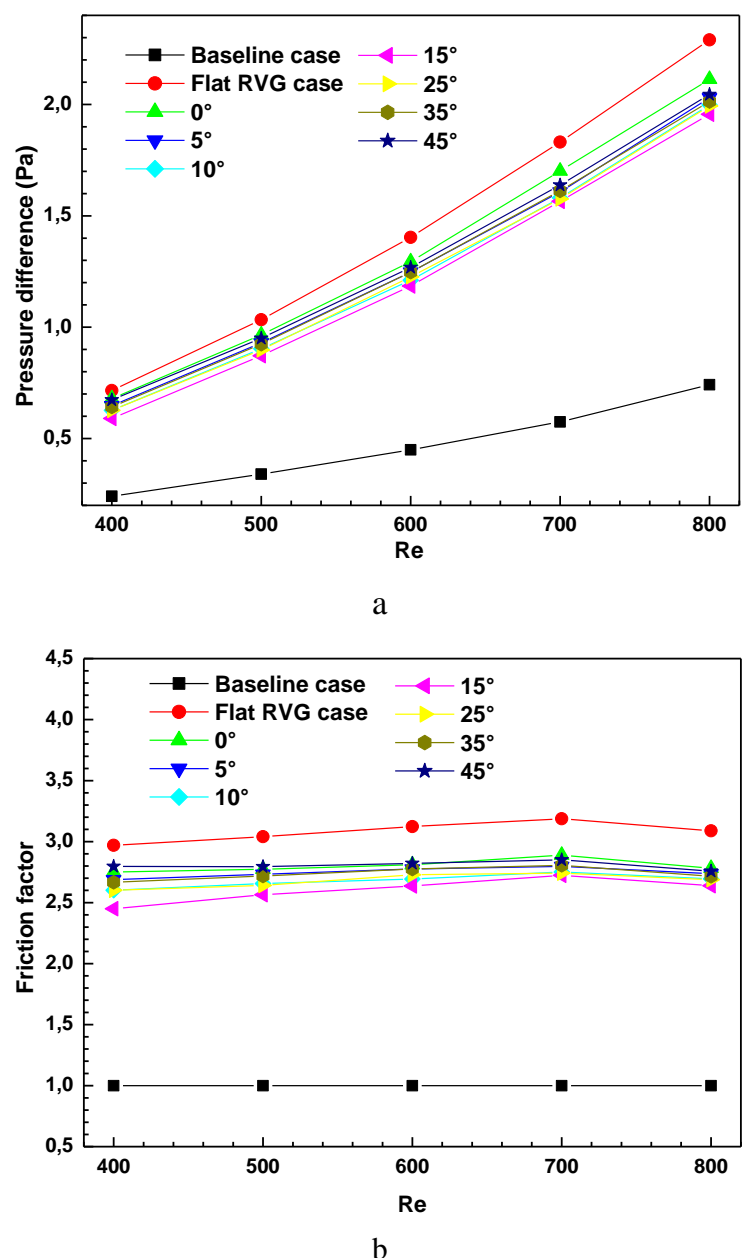

Fig. 7 Pressure drop (a) and Friction factor (b) versus Re number for VGs

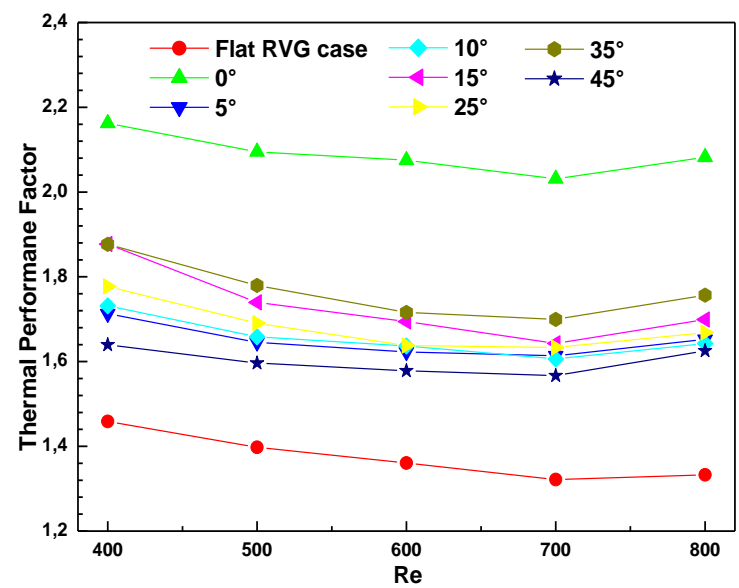

Fig. 8 Thermal performance factors (TPF) versus Re number for VGs

The variation of thermal performance factor (TPF) for air flowing in fin-and-tube heat exchangers with isosceles vortex generators (IVGs) is shown in Fig. 8. In 
the figure, the performance factor is superior than 1 for all cases. Hence, the IVGs merit enhancing the thermal performance in the fin-and-tube heat exchangers. For a better case selected in this study, the IVGs of $\alpha=0^{\circ}$ assured the highest performance factor. The enhancement factors vary between 2.1 and 2.15, depending on the Reynolds number values. Where, the maximum values of the thermal performance factor is about to 2.15 at $R e=400$.

\section{Conclusions}

Thermal and dynamic characteristics of a new design of VGs of isosceles shape placed in fin-and-tube heat exchangers are studied. The conclusions are summarized as follows:

1. The isosceles vortex generator (IVGs) disposed on the fin surface provide a convergent portion can guide the fluid flow towards the tube wall, which helps to reduce the zones of weak velocity behind the tubes.

2. Decreasing of the VGs size helps to reduce the penalty of pressure drop and keeping the thermal performance to high levels.

3. Comparing with the Baseline case, the IVG of $\alpha=0^{\circ}$ achieve a percentage of $95 \%$ of heat transfer coefficient and associated 2.8 times of pressure drop penalty.

4. Thermal enhancement factor (TPF) for the all IVGs is much higher than unity and its maximum value is about 2.15 at $\alpha=0^{\circ}$, indicating higher thermal performance over the Baseline case. Therefore, this case is recommended to enhance the thermal performances of the finand-tube heat exchangers.

\section{References}

1. Zhou, G.; Ye, Q. 2012. Experimental investigations of thermal and flow characteristics of curved trapezoidal winglet type vortex generators, Appl. Therm. Eng 37: 241-248.

http://dx.doi.org/10.1016/j.applthermaleng.2011.11.024

2. Wang, C.C.; Lo, J.; Lin, Y.T.; Wei, C.S. 2002. Flow visualization of wave-type vortex generators having inline fin-tube arrangement, Int. J. Heat Mass Transf 45: 1933-1944.

http://dx.doi.org/10.1016/S0017-9310(01)00289-7.

3. Wang, C.C.; Lo, J.; Lin, Y.T.; Wei, C.S. 2002. Flow visualization of annular and delta winglet vortex generators in fin-and-tube heat exchanger application, Int. J. Heat Mass Transf. 45: 3803-3815. http://dx.doi.org/10.1016/S0017-9310(02)00085-6.

4. Goldstein, J.L.; Sparrow, E.M. 1977. Heat/mass transfer characteristics for flow in a corrugated wall channel. J. Heat Transf. 99: 187-195. http://dx.doi.org/10.1115/1.3450667.

5. Yun, J.Y.; Lee, K.S. 1999. Investigation of heat transfer characteristics on various kinds of fin-and-tube heat exchangers with interrupted surfaces, Int. J. Heat Mass Transf. 42(13): 2375-2385. http://dx.doi.org/10.1016/S0017-9310(98)00310-X.

6. Tiggelback, S.; Mitra, N.K.; Fiebig, M. 1994. Comparison of wing-type vortex generators for heat transfer enhancement in channel flows, J. Heat Transf 116(4): 880-885.

http://dx.doi.org/10.1115/1.2911462.

7. Guzman, A.M.; Amon, C.H. 1996. Dynamical flow characterization of transitional and chaotic regimes in converging-diverging channel, J. Fluid Mech 321: $25-57$.

http://dx.doi.org/10.1017/S002211209600763X.

8. Fiebig, M.; Valencia, A.; Mitra, N.K. 1993. Wingtype vortex generators for fin-and-tube heat exchangers, Exp, Thermal Fluid Sci 7(4): 287-295.

http://dx.doi.org/10.1016/0894-1777(93)90052-K.

9. Valencia, A.; Fiebig, M.; Mitra, N.K.; Leiner, W. 1992. Heat transfer and flow loss in a fin-tube heat exchanger element with wing-type vortex generators, Inst. Chem. Eng. Symp. Ser. 129(1): 327-333.

10. Sparrow, E.M.; Comb, J.W. 1983. Effect of interwall spacing and fluid flow inlet conditions on corrugated wall heat exchanger, Int. J. Heat Mass Transf 26: 993-1005. http://dx.doi.org/10.1016/S0017-9310(83)80124-0.

11. Nishimura, T.; Murakami, S.; Arakawa, S.; Kawamura, Y. 1990. Flow observations and mass transfer characteristics in symmetrical wavy-walled channels at moderate Reynolds numbers for steady flow, Int. J. Heat Mass Transf 33: 835-845.

http://dx.doi.org/10.1016/0017-9310(90)90067-5.

12. Rush, T.A.; Newell, T.A.; Jacobi, A.M. 1999. An experimental study of flow and heat transfer in sinusoidal wavy passages, Int. J. Heat Mass Transf 42: 1541-1553.

http://dx.doi.org/10.1016/S0017-9310(98)00264-6.

13. Lau, S.; Meiritz, K.; Ram, V.I.V. 1999. Measurement of momentum and heat transport in the turbulent channel flow with embedded longitudinal vortices, Int. J. Heat Fluid Flow 20: 128-141. http://dx.doi.org/10.1016/S0142-727X(98)10052-8.

14. Krishne Gowda, Y.T.; Patnaik, B.S.V.P.; Aswatha Narayana, P.A.; Seetharamu, K.N. 1998. Finite element simulation of transient laminar flow and heat transfer past an in-line tube bank, Int. J. Heat and Fluid Flow 19: 49-55. http://dx.doi.org/10.1016/S0142-727X(97)10005-4.

15. Iacovides, H.; Launder, B.; West, A. 2014. A comparison and assessment of approaches for modeling flow over in-line tube banks, Int. J. Heat and Fluid Flow 49: 69-79.

http://dx.doi.org/10.1016/j.ijheatfluidflow.2014.05.011.

16. He, Y.L.; Han, H.; Tao, W.Q.; Zhang, Y.W. 2012. Numerical study of heat-transfer enhancement by punched winglet-type vortex generator arrays in finand-tube heat exchangers, Int. J. Heat Mass Transf 55: 5449-5458.

http://dx.doi.org/10.1016/j.ijheatmasstransfer.2012.04.0 59.

17. Li, M.J.; Zhou, W.J.; Zhang, J.F., Fan, J.F.; He, Y.L.; Tao, W.Q. 2014. Heat transfer and pressure performance of a plain fin with radiantly arranged winglets around each tube in fin-and-tube heat transfer surface, Int. J. Heat Mass Transf 70: 734-744. http://dx.doi.org/10.1016/j.ijheatmasstransfer.2013.11.0 24.

18. Gholami, A.A.; Mazlan Wahid, A.; Mohammed, H.A. 2014. Heat transfer enhancement and pressure drop for fin-and-tube compact heat exchangers with wavy rectangular winglet-type vortex generators, Int. Comm. Heat Mass Transfer 54: 132-140.

http://dx.doi.org/10.1016/j.icheatmasstransfer.2014.02. 
016.

19. Chu, P.; He, Y.L.; Lei, Y.G.; Tian, L.T.; Li, R. 2009. Three-dimensional numerical study on fin-and-ovaltube heat exchanger with longitudinal vortex generators, App. Therm. Eng 29: 859-876. http://dx.doi.org/10.1016/j.applthermaleng.2008.04.021

20. Li, L.; Du, X.; Zhang, Y.; Yang, L.; Yang, Y. 2015. Numerical simulation on flow and heat transfer of finand-tube heat exchanger with longitudinal vortex generators, Inter. J. Thermal. Sci 92: 85-96. http://dx.doi.org/10.1016/j.ijthermalsci.2015.01.030.

21. Wahid, M.A.; Gholami, A.A.; Mohammed, H.A. 2013. Numerical study of fluid flow and heat transfer enhancement of nanofluids over tube bank, Appl. Mech. Mater 388: 149-155.

http://dx.doi.org/10.4028/www.scientific.net/AMM.388 .149 .

22. Zukauskas, A. 1987. Heat transfer from tubes in cross flow, Adv. Heat Tran 18: 87-159.

23. Sinha, A.; Ashoke Raman, K.; Chattopadhyay, H.; Biswas, G. 2013. Effects of different orientations of winglet arrays on the performance of plate-fin heat exchangers, Int. J. Heat Mass Transf 57(1): 202-214. http://dx.doi.org/10.1016/j.ijheatmasstransfer.2012.10.0 34.

24. He, Y.L.; Chu, P.; Tao, W.Q.; Zang, Y.W.; Xie, T. 2013. Analysis of heat transfer and pressure drop for fin-and-tube heat exchangers with rectangular winglettype vortex generators, Appl. Therm. Eng. 61(2): 770783.

http://dx.doi.org/10.1016/j.applthermaleng.2012.02.040

25. Tian, L.; He, Y.; Tao, Y.; Tao, W. 2009. A comparative study on the air-side performance of wavy fin-andtube heat exchanger with punched delta winglets in staggered and in-line arrangements, Int. J. Therm. Sci. 48(9): 1765-1776.

http://dx.doi.org/10.1016/j.ijthermalsci.2009.02.007.
D. Sahel, R. Benzeguir, T. Baki

\section{HEAT TRANSFER ENHANCEMENT IN A FIN AND TUBE HEAT EXCHANGER WITH ISOSCELES VORTEX GENERATORS}

S u m m a r y

A numerical study was carried out to analyze the thermal and dynamic performances of fin-and-tube heat exchanger provided with vortex generators (VGs) presented in this work. The VGs presented as a new design of isosceles shape of attack angles $\alpha=0^{\circ}$ (Simple vortex generator), $5^{\circ}, 10^{\circ}, 15^{\circ}, 25^{\circ}, 35^{\circ}$ and $45^{\circ}$. The computations based on a finite volume method with the SIMPLE algorithm have been conducted for the air flow in terms of Reynolds numbers ranging from 400 to 800 . The heat transfer coefficients and pressure losses presented in terms of Nusselt number $(N u)$ and pressure difference $(\Delta P)$, respectively. The results show that the isosceles vortex generator (IVG) of $\alpha=0^{\circ}$ presents an encouraging increase in heat transfer coefficients by $95 \%$, and a moderate pressure drop penalty tend to 2.8 times compared with the Baseline case (tube without VGs), respectively. In addition, the IVG of $\alpha=0^{\circ}$ assured the highest factors of thermal performance vary between 2.1 and 2.15 depending on the Reynolds number values.

Keywords: Fin-and-tube, heat exchanger, heat transfer, isosceles vortex generators, winglets.

Received May 11, 2015

Accepted September 17, 2015 